\title{
Geoscience Discipline Construction Against the Double-Class Background: A Case from China University of Geosciences, Beijing
}

\author{
Yinhong Wang ${ }^{1, a, *}$ and Li Wan ${ }^{1}$ \\ ${ }^{1}$ Discipline Construction Office, China University of Geosciences,, Beijing, China

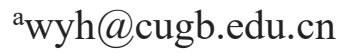 \\ *corresponding author
}

Keywords: Double-Class, China University of Geosciences, Beijing, Geosciences, Discipline Construction

\begin{abstract}
Combined with the specific meaning and construction background of the double-class colleges and universities, this paper discusses the construction and development of geoscience discipline of China University of Geosciences (Beijing) (CUGB). Based on the predominant specialties of geology, and geological resources and geological engineering, CUGB has formed its own disciplinary characteristics and make great efforts to speed up the construction of the world-class university in Earth Science. And it is obvious that CUGB has made remarkable achievements in the field of geosciences, some of its scientific researches results are well acknowledged and awarded, and the level and quality of science and technology has experienced a great improvement. For the selected specialties, this paper also analyzes the necessity of discipline construction, and discusses the development plans of discipline construction of geosciences in CUGB, including the characteristic specialties, the geographical advantages, and the regional and international cooperation.
\end{abstract}

\section{Introduction}

In 2015, the State Council issued the Overall Plan for Coordinating the Development of World-class Universities and Disciplines (hereinafter referred to as Plan), which means that the development of Chinese higher education has advanced to a new era. According to the Plan, the construction of the double-class universities and disciplines is a major strategic decision. This is of great significance for improving the level of education in our country, enhancing the core competitiveness, and laying the foundation for long-term development [1,2]. The Plan revolves around the key requirements of the Chinese characteristics and world-class, and it also focuses on 10 significant tasks in terms of construction and reform, at the same time, the overall goal of the double-class construction of a threestep model is defined according to the Chinese actual conditions. CUGB, a traditional university of geosciences, has cultivated a large number of geologists, geological workers, and even state leaders to our country, and it should realistically strengthen the construction of preponderant disciplines according to its own characteristics and strive to construct the world-class university in Earth Science.

\section{The Definition Of Double-Class}

In order to better put on the path to the double-class construction, we should have a relatively clear understanding of the double-class universities. Regarding the world-class universities, Shang Xiaohui et al. (2017) proposed that the connotation of world-class universities based on summarizing the researches of many scholars is that: at the institutional level, there must be a world-class school-running philosophy, perfect modern university system, and high-class university management; at the educational level, there must be world-class disciplines, scientific research achievements, and teacher stuff $[2,3]$. 
No matter whether it is at an institutional or an educational level, all the factors are concentrated on the essential goal that is to cultivate talents for universities and to constitute a truly world-class university in the end. Zhou Guangli et al. (2016) obtained four criteria for the world-class disciplines on the base of research and analysis, including the top-ranking academic teams, classic scientific research results, high-class college students, and first-rate academic reputation [2].

The discipline construction and the university development are a close combination process, and both have certain characteristics of level. Discipline is the foundation of the colleges and universities, especially in the higher research-oriented universities, and it has a direct effect on education and personnel training $[3,4]$. For every college and university, the construction of the world-class discipline is an urgent requirement to achieve its mission and improve the level of scientific research [5].

Only through improving the Chinese disciplines to the level of world-class, it will be possible for Chinese colleges and universities to approach the level of the double-class universities; however, it takes time and more investments to accomplish such a great achievement.

\section{The Double-Class Disciplines Of Cugb}

In 2017, the Ministry of Education announced the list of the construction of the double-class universities and double-class disciplines. In CUGB, the geology and geological resources and geological engineering majors are honored to be selected.

As the cradle of training Chinese talents of geoscience and an important base for geoscience researches, CUGB adheres to the excellent motto, namely, hard work, plain living, seeking truth and pragmatic, and it is consistently committed to cultivate innovative talents and build a high-level research university. The selected results of two double-class disciplines are not only a definite recognition of CUGB, but also an indispensable development opportunity that should be seized in future.

The preponderant disciplines are always the direction in which we concentrate our strength on development and we can better meet the original intention of the double-class construction and truly achieve the double-class standard based on our own characteristics of education.

\section{The Necessity Of Double-Class Discipline Construction}

Judging from the list of the double-class disciplines, the geoscience disciplines of several universities have been successfully selected. Considering that the two majors, namely geology and geological resources and geological engineering in CUGB are also selected, they are not only a fabulous opportunity for development, but also a challenge. Whether in terms of the history of running a university or the current development trend, CUGB, as a traditional university of geosciences, has made remarkable achievements in recent years. CUGB will never stand, because this double-class construction will only allow it to keep on moving and achieve even more impressive results in future. At the same time, discipline construction should be closely linked with social development.

The disciplines set up by colleges and universities are not only applied to the academic researches, but also must be more oriented to the society and cultivate the innovative talents for the social development. Although the current geology industry is tepid, the stable development of the society cannot sustain without the support of the resources. Hence, the demand for geological talents will not be reduced. Additionally, environment is also a major issue that needs to be solved urgently. However, this issue has lasted for so long and requires us to make more efforts to obtain an improvement.

We can obviously know that CUGB has made a series of breakthrough and new achievement in the field of the science and technology in recent years, and that the comprehensive strength and competitiveness of CUGB has experienced a continuous increase.

Firstly, CUGB have conducted 499 research projects funded by the National Natural Science 
Foundation of China, with a tendency of from 72 projects in 2011 to 92 projects in 2017.

Secondly, the level and quality of science and technology achievements is unceasingly improved. We have published 4418 SCI papers in total including 3703 foreign periodicals SCI papers with a great increasing trend from 2011 to 2017. In other words, approximately 84 percent of all papers are published in the foreign periodicals.

Thirdly, CUGB has gained more and more science and technology awards. The number of State Science and Technology Awards amounts to 8 while the number of Province (or Ministry) Science and Technology Awards amounts to 66 from 2011 to 2017. Therefore, the academic achievements made by CUGB in recent 7 years are remarkable. In order to sustain great progresses, CUGB must be absorbed in making the double-class discipline better.

In addition, only taking geology into account, except for CUGB, geology of Peking University, Nanjing University, China University of Geosciences, Wuhan, Northwest University, and Chengdu University of Technology have been the selected list of double-class construction. That is to say, these universities also do well in the field of earth science and own specialties that they have great advantages. So CUGB will definitely face direct challenges from other sides while pursuing for a fair competition. There is no doubt that CUGB is quite confident and has the reason to build better and truly come up to the double-class standard, not just being on the double-class list.

Consequently, it is very necessary for CUGB to construct the double-class disciplines at this new stage.

\section{Suggestions}

Under the background of national double-class development, we should closely link our own specialties with the related geoscience disciplines to form a large and complete group of geosciences and complete the realization of the goal of the world-class university in Earth Science at an early date. Meanwhile, an educational environment with an excellent academic environment is most conducive to the discipline construction and an outstanding group of teachers also partly can make a difference to the development of a discipline. Under such a condition, CUGB should strength to construct geoscience disciplines, and develop a high-level research university. We suggest the development plans of discipline construction of geosciences in CUGB from the following aspects.

\section{A. Taking Two Specialties of the Geology and Geological Resources and Geological Engineering as Predominant Development}

With two specialties of the geology and geological resources and geological engineering selected as national double-class strategy, the discipline construction of geosciences in CUGB has become a key topic. However, it is very difficult for the university to take all geoscience disciplines into account and have all majors constructed together. Therefore, it is necessary to strengthen the construction of the predominant and characteristic disciplines to form distinct features.

In other words, CUGB must guarantee that there are enough investments and supports for the two double-class disciplines. Related disciplines such as geographic information systems, land resource management, and quaternary major should also have been developed effectively. The coordinative development between geoscience disciplines and extensive disciplines of earth science should also exist. In addition, the innovative teams should be constructed on the combination of several disciplines and corporation of more than two research-oriented teachers so as to achieve better academic results. This form of research is surely new and original, but it is more like an academic system and has considerable academic cohesion [6].

With double-class disciplines as the leading advantage, CUGB will take countermeasures to develop the construction of geoscience disciplines and other crossing disciplines associated with the innovative 
teams, expand the field of geosciences, and form a systematic and perfect system of earth science [7].

\section{B. Focusing on Geographical Advantages}

At present, China University of Geosciences (Beijing) and China University of Geosciences (Wuhan) are separate. Compared to Wuhan campus, CUGB has more relative advantages of geography. As an international city and a center for political, economic and cultural exchange, Beijing is easier to attract more scholars and gather more academic exchange activities and conferences on geoscience than that of other universities. This, in turn, is more likely to create an active research environment that is beneficial to conduct scientific researches.

More and more visiting professors carry out the research and give academic lectures in the universities of geosciences, which promote the exchange of knowledge about earth sciences and stimulate the wisdom of thinking. Considering the geographical advantages over other cities, it will be reasonably enough for CUGB to have a further development of geosciences. This is such a great advantage of which we can take full advantage to promote higher education and construct double-class disciplines.

In short, CUGB should focus on the existence of geographical advantages, grasp development opportunities, and keep in hot pursuit to gain the world-class level in the field of earth sciences.

\section{Combination of Research and Education Together}

The purpose of the discipline construction of geosciences is nothing more than scientific researches and personnel training. However, some teachers devote themselves to conducting research, whereas others are accustomed to teaching in the colleges and universities. In the course of the discipline construction of geosciences, all of them should be placed in the same important position, and there should be circumstances that favor each other.

The disciplines can reflect that core competitiveness of the colleges and universities, and one of the important tasks in the colleges and universities is to educate students and cultivate high-quality innovative talents for the society [8]. Based on the discipline construction, related scientific research can be well conducted. Platforms such as the state key laboratory should be constructed to provide suitable development opportunities for the researchers and graduates. It is well known that graduates are very important power for scientific research, thus the education quality of graduates is one of the key indicators of the discipline construction and reflect the level of the discipline construction in colleges and universities. Nowadays, whether the college or university should cultivate innovative talents for social development and improve its level of scientific research at the same time.

In the course of education, there is a possibility that some teachers and researchers may realize that teaching is learning and put this into practice. The connection between scientific researches and education should not be ignored. Therefore, we must ensure that scientific researches and education in an equally important position, fully mobilize the enthusiasm of each teacher to engage in researches and education as well as make better use of their advantages. And CUGB also should take more effective countermeasures to adjust the current management of scientific researches and education [9, 10]. To create a more rational management mechanism of science and technology will be a good way of promoting the combination of scientific research with education.

\section{Regional and International Cooperation}

Based on the above-mentioned geographical advantages, as well as the differences between a university and an enterprise, CUGB can establish a stable cooperation with local geological universities, enterprises and even some universities overseas to get perfect win-win cooperation. Anyway, much attention needs to be paid to the corporation with other colleges and universities in the manner of graduate co-cultivation or discipline construction, which may lead to a great improvement of geoscience.

In terms of personnel training, academic exchanges, and scientific researches, CUGB will actively 
cooperate with each other and introduce high-level talents into the school to further enhance the influence and competitiveness of the relevant disciplines [11]. In addition, in order to further enhance collaboration with other colleges and universities and jointly develop earth science, it is very necessary to provide a good platform for geoscience researches and education, and an international platform for graduate education such as studying abroad and exchanging students [12].

The active cooperation between CUGB and other geoscience universities in the world will not only promote the development of disciplines, but also help other geoscience universities improve the academic level to some extent. Such a regional and international cooperation is undoubtedly a win-win situation.

\section{Conclusions}

The discipline construction is a key factor in promoting the academic level of the university, particularly a higher research-oriented university. The construction of two double-class disciplines in CUGB, namely the geology and geological resources and geological engineering, is the predominant orientation. Taking the lead of double-class discipline construction and creating such platforms of collaborative innovation will make the geoscience of CUGB gain a better improvement. In order to provide the best environment for scientific researches, CUGB must speed up the construction of the excellent academic environment and discipline platform. In addition, it is quite necessary for CUGB to construct the innovative teams and conduct more research subjects on geoscience to improve the competitiveness. In a word, discipline construction of geosciences in CUGB is of great importance and meaningful because it is the foundation of constructing a world-class university. Great importance should be attached to the construction of double-class discipline and graduate education because of its essential purpose of a high-level research-oriented university. Though there are many challenges, CUGB is now on the way of development, and will have a bright future.

\section{References}

[1] X.H. Shang and J.Q. Jiang, "The connotation, essence and construction methods of the world-class university", Chinese University Technology Transfer, no.1, pp.14-18, 2017.

[2] G.L. Zhou and J.X. Wu, "What is the world-class discipline", China Higher Education Research, no.1, pp.65-72, 2016.

[3] Y.H. Ni and Y.L. Wang, "The practice unity of discipline construction and personnel training in the background of double-class strategy", Jiangsu Higher Education , no.2., pp.7-10, 2017.

[4] L. Wan and Y.H. Wang, "Analysis of discipline strength in higher universities based on state science and technology awards", Bulletin of National Natrual Science Foundation of China, no. 5, pp.293-296, 2011.

[5] T.Q. Ma, "Double First-class construction and university development", Journal of national academy of education administration, no.9, pp.9-14, 2016.

[6] J. Deng, "Subject construction and graduate education”, Chinese Geological Education, no.2, pp.1-4, 2007.

[7] J. Deng, "Taking the lead of discipline construction and promoting the core competence of the university", Chinese Geological Education, no.4, pp.10-12, 2012.

[8] H.X. Jiang, "Strengthen the guidance of education and promote double-class discipline construction", China University Teaching, vol.11, pp.44-46, 2016.

[9] Y.H. Wang, L. Wan and X.H. Lei, "Countermeasures and suggestions for improving management of science and technology achievements in higher universities of geosciences at new stage", International Conference on Economic and Information management, pp.67-70, 2011.

[10] Y.H. Wang, "Discussion on reform and innovation of scientific and technological management in 
higher universities at new stage", Chinese Geological Education,vol.16, pp.98-101, 2007.

[11] L.Q. Lin, "Discipline construction of high-level university under the "double-class" strategy vision", University Logistics Research, no.4, pp.101-111, 2016.

[12] Y.H. Wang, L. Wan and X.H. Lei, "A brief discussion on how to construct the scientific and technological platforms in colleges and universities", International Conference on Economic and Information management, pp.62-66, 2011. 